This is an electronic reprint of the original article. This reprint may differ from the original in pagination and typographic detail.

Author(s): Urquía-Grande, Elena; Rautiainen, Antti; Pérez-Estébanez, Raquel

Title: The effectiveness of rural versus urban nonprofit organisations in the Democratic Republic of Congo

Year: $\quad 2017$

Version:

Please cite the original version:

Urquía-Grande, E., Rautiainen, A., \& Pérez-Estébanez, R. (2017). The effectiveness of rural versus urban nonprofit organisations in the Democratic Republic of Congo.

Third World Quarterly, 38(9), 2129-2142.

https://doi.org/10.1080/01436597.2017.1322464

All material supplied via JYX is protected by copyright and other intellectual property rights, and duplication or sale of all or part of any of the repository collections is not permitted, except that material may be duplicated by you for your research use or educational purposes in electronic or print form. You must obtain permission for any other use. Electronic or print copies may not be offered, whether for sale or otherwise to anyone who is not an authorised user. 


\title{
The effectiveness of rural versus urban Non-For-Profit Organizations in the Democratic Republic of Congo
}

\begin{abstract}
The Democratic Republic of Congo (DRC) is a country with high natural resources but it has suffered from decades of civil wars and social turmoil being heavily aid-dependent. In the DRC, several Non-For-Profit Organizations (NPOs) are major players in fighting poverty and enhancing welfare. This research aims to analyse the effectiveness of small NPOs in improving poor peoples' lives through health, education and economic activities. Two NPOs working in the DRC, one in a rural and the other in an urban area, are compared by researching the aid sites and surveying 201 households (aid beneficiaries). Our case observations and the survey results facilitate analysing the mission accomplishment, effectiveness and accountability of the NPOs although we admit that the DRC conditions make exact measurements difficult. Multivariate analyses are used to study the differences in aid impacts. There are significant differences in the beneficiaries' perception of the NPO effectiveness in improving health while no significant differences in education impact were found. This is probably because both case NPOs have succeeded in getting a large proportion of the children of their area registered in the education centres created by the NPOs. Differences were observed in the accountability and reporting style of the NPOs.
\end{abstract}

Keywords: NPO; DRC; impact; mission accomplishment; health and education; effectiveness; accountability. 


\section{Introduction}

The Democratic Republic of Congo (DRC) is suffering from a prolonged economic and social crisis due to several civil wars during the past twenty years. Even before the civil wars the country has witnessed a long history of violence and exploitation in the forms of slave trade, Belgian imperialism, corruption and tribal disputes. Despite these economic and political difficulties, the rich natural resources in the DRC have facilitated a reasonable Gross Domestic Product (GDP) growth rate of 4-5\% annually. The last few years have, however, been characterized by persistent high inflation, slow growth or stagnation, unemployment and declining real incomes. Due to the high inflation the prices for goods and services (including public sector services) are often set in hard currencies. By contrast, wages and salaries are expressed in local currency, and represent very little in real terms, even for the top-level civil servants and private sector employees. In addition, the wages and salaries are not paid regularly, and this makes it difficult for households, struggling for survival, to cope with health and education costs. The costs for sending one child to a good school and taking care of his/her health can easily be more than double of the average monthly pay ${ }^{1}$. In the DRC, many development and cooperation forms are in a process of transition as government policies, cooperation forms and foreign aid amounts change.

This research focuses on little researched area: the effectiveness and accountability evaluation of two small NPOs, one working in urban and the other in more rural DRC conditions. The NPOs offer services and cooperation, thereby improving the household life of the poorest. However, the difficult circumstances and cultural differences among the tribes and regions complicate performance measurement and accountability analyses. Earlier findings suggest that NPOs which are small, free and swift can make development activities more effectively. Further, there are several factors which determine NPO effectiveness in developing countries, such as mission accomplishment, responsibility, transparency, accountability and Information 
and Communication Technologies (ICT) use, but additional research on these factors has been called for ${ }^{2}$. Thus our research questions are:

RQ1: Are there differences in the accountability and reporting styles and in the beneficiaries' perceived health or educational impact between the rural and the urban NPO?

RQ2: Which variables determine the beneficiaries' health and educational improvement perception?

The empirical part of this research covers the education and health services of two NPOs that are small and operate in poor DRC areas. The case NPO employees have low accounting skills to report their objectives, or to measure their outcomes. Drawing data from observations, internet pages of the NPOs, quantitative survey and qualitative interviews with the NPO managers and the surveyed households, this research aims at understanding the Congolese NPO landscape in development activities, practices and outcomes. Our analysis is expected to foster the comparability of NPOs and eventually to foster their value-added aid activities. Our comparative NPO case analysis also suggests that the distinction between local and international, urban or rural NPOs is blurry, illustrating the importance of looking beyond NPO types in order to capture the dynamics of development factors and NPOs influence.

This research article is structured as follows. First a brief bibliographic review is made about NPOs and their impact on development. Then the two case studies are presented. The NPOs receive a large part of their funding from Spanish private donors and both have an educational centre (school and orphanage), both manage a small hospital for basic health care, and the urban NPO also has a medicine dispensary. The urban NPO also owns its small hospital dedicated for pregnant women and diabetes patients. After introducing the data, multivariate analyses are run in order to compare the similarities and differences in the NPO effectiveness, such as the impact on the household health, education and economic levels, which may also 
measure the NPO mission accomplishment. Findings show that the urban NPO was more effective in health improvement while the rural NPO had a slightly higher impact on the education of its beneficiaries. Further, we found differences in the urban and rural contexts, in the NPO leadership profiles and in their reporting practices. Our qualitative data analysis suggests focusing efforts especially on issues in both education and health. Finally, the measurement of NPOs effectiveness and accountability is discussed and conclusions are drawn. This research contributes to the analysis of NPO effectiveness in health and education field, especially by casting light on the difficult operating context of improvement and poverty alleviation in the DRC.

\section{NPO context}

International Development cooperation is a dynamic system involving multiple actors ${ }^{3}$. The role of a single NPO in development cannot be easily measured because there are several other actors and organizations working in the field of health and education, for example. NPOs are private and autonomous organizations, often serving as major and efficient service providers for the poor people ${ }^{4}$. According to World Bank definition, NPOs are organizations involved in providing services to relieve suffering, promoting the interests of the poor and in undertaking community development with altruism and voluntarism ${ }^{5}$. In the past three decades, however, globalization and democratization in the developing countries have brought about changes in NPO types. The rise of NPOs - both in number and in variety - gives the NPOs a possibility to offer services, mostly health care and education, that the government or other companies cannot provide ${ }^{6}$. International development cooperation is a continuous fight against poverty and human deprivation, and what individual countries do to promote economic growth, generate jobs and provide social services in a democratic and participatory way will have a decisive effect on the promotion of people's rights and local development ${ }^{7}$. 
Some authors are very sceptic in the aid assessment at a macro level but believe in NPO work at a micro level ${ }^{8}$. At a macro level, aid is analysed considering for example the monetary amounts and investigating what countries are the donors ${ }^{9}$ but this is far away from the "grass root" experience. Some researchers suggest that NPOs need to professionalise in order to become more efficient but, at the same time, maintain their grass root expertise ${ }^{10}$. The number and variety of NPOs suggests, however, that there can be differences in the effectiveness and even in the motives of NPOs performance. Hence, NPOs are often required, by their multiple stakeholders, to meet short-term objectives in the form of results and valuefor-money indicators as well as to provide information about the achievement of their longterm aims of society ethics and transformation. Here is a classic information asymmetry problem meaning that the small NPOs have more knowledge and expertise of their context than big NPOs, governments or donors. After the financial crisis, and the resulting financial distress also in Europe, many donors call for more information about the NPOs performance and cost-effectiveness in order to avoid excessive spending. However, if the humanitarian workers are preparing performance measurement and control reports and finding out key performance indicators, a part of their working effort will be used in non-core operations, gradually lowering core-service effectiveness and perhaps even the perceptions of aid beneficiaries $^{11}$. Therefore research is needed to find comparable but easy-to-use performance measures and thus close the gap between the interests of NPOs, aid beneficiaries, donors and Governmental institutions. Accounting academics can facilitate closing this gap and help NPOs to easily and comparatively publish their value-added activities on health, education and economics as well as to show their value in the development processes to the stakeholders, such as the donors.

The individual leader is central in shaping the mission accomplishment, accountability and success of small NPOs in the Third World context ${ }^{12}$. Different leadership styles are contingent on the context in which they are applied. NPO leaders in the DRC must currently adapt to new 
leadership roles with multiple pressures, such as political instability, growing service and reporting needs, changing infrastructure, inflation, financial shortfalls and tight project schedules. This may have a negative impact on the ability of the leaders to pursue their long term goals or to achieve an acceptable level of services or reliability as judged by the NPO stakeholders.

Accounting research might facilitate small NPOs to be more accountable and transparent, for example by training them on how to develop their financial statements, make investments, and disclose performance information. In order for the NPOs to continue and develop their valuable work, they increasingly need to prove their legitimacy and organize their work effectively ${ }^{13}$. NPO accountability means that the individuals and organizations need to report to the stakeholders and authorities to whom they are responsible for their activities. This includes disclosing what they do, how they account for the outcomes, and if they operate in accordance of the laws and human rights. Furthermore, if the NPOs shared more information with each other the best practices found might improve performance and overall NPO impact. There are authors who suggest that NPO effectiveness is best measured with a balance between non-financial and financial indicators ${ }^{14}$.

Action-at-a-distance is a term used to portray the problems of accountability and control in circumstances of distance, which includes both physical and cultural distance, for example between the DRC and Spain ${ }^{15}$. In controlling action at a distance, the possible difficulties relate also to trust and power and here accounting documents serve as tools that both guide and partly create the activities of the NPOs in the eyes of the distant stakeholders. Performance measurement documents do not necessarily convey any objective truth but their meaning is created in a process of disclosure and interpretation ${ }^{16}$. Accounting numbers and other control system information, for example in internet pages, may be used in affecting the perceptions and the interests of distant stakeholders in the changing circumstances ${ }^{17}$. 
To summarize, in light of the action-at-a-distance and information asymmetry discussions above, NPO accountability is a challenging area of analysis. The need for research in this area is visible, for example, in the fact that the aims of the stakeholders, such as partners, funders and the people may differ. This may blur the management focus and create problems in terms of visibility, credibility and NPO sustainability ${ }^{18}$. Moreover, accountability relations may become complex and NPO actions can be guided by several inconsistent stakeholder demands, for example in terms of strategic or short-term performance ${ }^{19}$. In parallel, to measure NPO legitimacy the focus may be on objective proof or perceptions, either locally (from the grass root point of view) or from a more distant view of governments and donors, often considered in terms of trust, reputation and transparency. With respect to transparency it is important how funds are spent, and what the NPOs are creating for their neighbourhood. All these aspects of accountability decide if the NPO is legitimated in the eyes of the stakeholders ${ }^{20}$. The advances in technology have opened new possibilities for generating and using information from many points of view. ICT tools may enhance NPO mission accomplishment, and attract donors to their projects. From a global view ICT holds a great potential for enhancing human development and economic growth ${ }^{21}$. Interestingly the case NPOs have a low level of ICT use and this can be a factor in their success. There is a long line of research analysing NPO success and failure with aggregate level cluster analysis ${ }^{22}$. In our research, the NPO success will be measured by local beneficiaries' perceptions and non-financial and financial indicator results ${ }^{23}$. Further, there is research about control systems and the processes of change $e^{24}$. Also we consider the developments in efficiency, accountability and NPO impact, which are partly analysed through output numbers and partly through qualitative data of the perceptions of the local NPO actors.

\section{Sample and methodology}


This comparative case research ${ }^{25}$ uses both quantitative and qualitative data but mainly we analyse household survey data collected from the two poor NPO areas in the DRC. The households were randomly chosen from the areas. A large part of the funding of these NPOs comes from Spanish donors who increasingly demand web-based information of NPO activities and accounting reports about operations and funds.

The household survey sample $(\mathrm{N}=201)$ consisted of 103 beneficiaries of the urban NPO from Mikondo, area (near Kinshasa, the capital city of the DRC), and 98 beneficiaries of the rural NPO from Ngandanjike area (relatively near Mbujimayi in the south of the DRC). Both NPOs are working in several fields such as children's education, health, agriculture, communications, women empowerment and infrastructure. The rural NPO was created in 2006 and its director is a Congolese priest. The urban NPO's director is a PhD in philosophy from an Italian University but his family lives in Spain, and the NPO was started in 2001.

Currently the rural NPO is helping the management of the hospital, facilitating micro-business start-ups for women, managing an orphanage for children, operating a local radio channel for news diffusion, and the NPO has also built a church. Three of the rural NPO volunteers conducted the survey data collection during two months. The urban NPO created a nursery and has enlarged it to education centre, now having more than 300 children registered. The urban NPO has also created a hospital, focusing on pregnancy and diabetes, and it manages a pharmacy in the area of Mikondo. The urban NPO is also involved in house-building in a cooperation project with a Spanish Architecture University. The urban NPO has recently started its operations also in a nearby rural area where it is replicating some of its projects. However, in this paper, we study only the more established operations in the Mikondo area.

The researchers wanted to analyse the NPO effectiveness going from accountability to the organization's impacts. Thus, several research tasks were implemented. First, a survey was designed and tested with experts in the area and then translated to French, which is the most 
common language in the area. The survey consisted on some socio-demographic questions and seven questions about the NPO aid in education and health. The survey was validated with several experts in the French language and content. The questionnaire took approximately 10 minutes to complete. The socio-demographic questions include age, gender, education level, and the number of siblings. The seven items about education and health include issues such as how many children went to the NPO school, how many family members went to the NPO medical centre, and the perception of health improvement since the NPO started managing the hospital. Each of the items was answered using a five-point Likert scale ( $1=$ Strongly Disagree, 2 = Slightly Disagree, $3=$ Neutral, 4 = Slightly Agree, 5 = Strongly Agree). A descriptive explanation of concepts was given to the people who were going to answer the survey in order to improve the quality of data collection and the reliability of the findings. Second, qualitative data was collected via discussions and e-mail correspondence with the NPO managers. There was also an open-ended section for qualitative comments in the survey because an aim was to collect also qualitative feedback from the households. The qualitative commentaries were summarized and analysed thereby enriching the view based on the quantitative results. Third, the internet pages of the NPOs were studied in order to analyse reporting and accountability.

The age of the survey respondents varied but was typically between 35 to 50 years. The number of siblings who were educated typically was between zero and 1 , while the number of siblings who work is typically 1 or 2 . The percentage of current or acute health problems in the families, is almost $100 \%$, the number of monthly visits to the hospital were at minimum four, while the number of visits to the pharmacy were between 6 and 15 . About $50 \%$ of the respondents were handling the family's economy and had at least some financial knowledge. When asked about the pharmacy the urban NPO has created a medicine dispensary and the number of visits made was typically from 6 to 10 monthly. However, the rural NPO has not created the medicine dispensary still so the number of visits was a bit lower and this question also received a lower answer percentage in the rural area (Figure 1). 


\section{Insert Figure 1}

July was the ideal month to pass the survey because during summer there are volunteers mainly from Europe who helped the surveyors. So both the volunteers and the NPO members passed the survey together. The questionnaires and the interviews were the key tools for data collection. Conducting the whole survey round lasted about a month due to the qualitative interview questions incorporated that usually took more than 10 minutes in addition to answering the quantitative questions. Once the questionnaires were returned, a database was created and multivariate statistics were run in order to answer the research questions. The qualitative commentaries were summarized and commented as an aid to the quantitative results. There were two questions asked about economic knowledge and decision-making in their households. The questions resulted in an interesting preliminary observation that, from the DRC households surveyed, quite equally men and women were in charge of the household economy. Usually, however, one of the parents makes most decisions about the children's schooling, household economy, and the health and nutrition issues. Finally, an intensive analysis of the NPO web-site activities publication was done in order to observe the level of NPO transparency, legitimacy and accountability.

\section{Findings}

A T-test for equality of means was done to analyse the NPOs, and significant differences were found (see Table 1). In the urban NPO, the age of the population was up to 50 , even to 70 years, while in the rural NPO the population age was typically between 20 to 35 years. In the urban NPO there were more female respondents than in the rural NPO. The number of siblings working was from 1 to 3 in the urban area, while almost none of the siblings were working, apart from family chores, in the rural neighbourhood. The results also show that the urban 
population has a perception of having a mediocre health improvement with the NPO's help, while the improvement among the rural population is perceived lower.

\section{Insert Table 1}

In order to demonstrate the NPO effectiveness on household health it can be noted from Table 1 that health problems are higher in the urban area, resulting in more visits to the hospital. The urban NPO has about 4 to 6 visits to the hospital while the rural NPO has only 0 to 1 visits. The distance to the hospital made no big difference between the NPO respondents (like it might have been expected). When asked about the results from the urban NPO director, he explained that many surveys were taken relatively near the hospital, so there can still be some bias related to the importance of the distance of the hospital. Some areas in the DRC may still be considered being out of the reach of medical services.

The NPO members and volunteers passed the majority of the surveys near the hospital and the pharmacy dispensary because there were more people and movement [than elsewhere].

A greater and more longitudinal survey needs to be done to reassure this result. Anyway, having a hospital in the area was more important than its exact distance. The urban NPO constructed a hospital of their own in order to alleviate the local population health problems. The rural NPO is helping to run a small hospital in the neighbourhood, but it is difficult to measure the exact NPO impact because the hospital is not fully finished and the hospital is not fully owned by the rural NPO but there are several kinds of voluntary workers and processes going on. The rural NPO director tells:

\footnotetext{
The NPO and its volunteers in these years have helped with the electrification of the hospital although we would like to assist the patients.
}

Some key variables with differences between the NPOs are education and the number of siblings working, in urban area there are more working opportunities (see Table 1). It is interesting note that the education level was higher in the rural neighbourhood (secondary 
level) while in the urban neighbourhood the education level on average was primary. However, no significant differences were found between the numbers of siblings educated. This is an interesting result and demonstrates that both NPOs are devoted to children's education centres (school and orphanage) as well as having them as nutritional centres. In fact both NPOs started the education centres as nutritional and shelter centres, then enlarged the operations towards educational at a nursery activities. With this holistic approach, several family members, but especially the children, can have an easy and nutritionally secured access to education. This issue can be seen as the main and most successful achievement of both NPOs although the education levels of the families (grown-ups) were different.

In order to observe the variables which determine the people's perception of education and health improvement a linear step-wise regression analysis was run. There were no statistically significant results with respect to education improvement. The factors determining the urban NPO recipients' perception of health improvement were the number of times they went to the hospital but not the number of times they visited the pharmacy or the number of medicines they consumed. Also the number of siblings working was not a determining variable (Table 2). The $R^{2}$ is of 0.934 which shows the robustness of the model. The "Coefficient $B$ " column in Table 2 shows that the beta for Gender is positive (0.424) and statistically significant $(p=0.000)$. This indicates that the health improvement perception was more positive among women. In addition there is a positive relationship between the health improvement perception and high education $(0.317, p=0.000)$, high number of visits to hospital $(0.261, p=0.015)$, and high number of visits to pharmacy $(0.128, p=0.076$, almost statistically significant).

\section{Insert Table 2}

In order to study NPO accountability, we analysed information published on the NPO web $\operatorname{sites}^{26}$. We observed that both NPOs define and disclose clear objectives each year. However the rural NPO discloses priorities and strategies and targets for forthcoming years, but the 
urban NPO does not. Both NPOs disclose information about their governing principles and rules, programmes and activities each year but only the rural NPO publishes the representation of stakeholders. The rural NPO has more networking activities which helps it having more and younger volunteers working with them. With regard to legitimacy, both neighbourhoods have trust in the NPO's democracy, integrity and reputation, and both of them have more than 10 years of "grass root" experience in the area. The urban NPO has more presence on-line, more press coverage of activities, and publishes a monthly newsletter online. The rural NPO makes more visible their social outcomes and discloses information based on focus areas.

\section{Insert Table 3}

The advance in technology has opened the possibility of generating and using information. ICT tools can enhance NPO reporting and attract donors ${ }^{27}$. Having checked the items in table 4 it was noted that the rural NPO seems more reliable while the urban NPO is more practice oriented. Interestingly these NPOs have low ICT use level and this can be a factor in their success in achieving financial resources. The urban NPO discloses a separate progress report and a newsletter, but the rural NPO does not. Further, there is no common reporting guidance for NPOs. Neither NPO publishes their financial statements. These findings suggest that NPOs in the developing countries may operate differently and without strict accountability but, in order to attract donors, still need to make some effort to communicate their goals, strategy, activities and achievements to stakeholders.

\section{Discussion and conclusions}

Small NPOs often have more knowledge and expertise of the "grass roots" where they work than large NPOs, governments or donors. Accounting research on local NPOs may facilitate bridging the research gaps regarding accountability, measurement of NPO mission 
accomplishment, government plans and donor expectations. Academics can help NPOs to focus their activities and to publish relevant information to donors about the value-adding activities on health and education and about the value of the NPO in question as a potential cooperation party for other development actors ${ }^{28}$.

In conclusion, our findings indicate that small NPOs can create positive effects on health and education in the DRC. We argue that a combination of long-term aid starting from nutrition, continuing with education and on to health centres seems to work in the poorest areas, especially among children. The work of the case NPOs supports this multifaceted view of wellbeing, and, based on the interviews, are on the right path in order to accomplish their mission and objectives. However, this paper shows that performance measurement, assessment of efficiency, and the collection and analysis of data can face great difficulties in conditions such as in the DRC. There is not enough performance data in order to judge the effects of the NPOs exactly, separate from other actors in the field. Further, the NPOs do not disclose detailed financial statements of their operations, leaving some ambiguity to accountability relations.

These NPO case studies suggest that the distinctions between (e.g. rural and urban) NPOs can be blurry in the DRC context, illustrating the importance of looking beyond any pre-set NPO typology to capture the dynamics of development operations and the impact on development. This research, however, was the first step to cover the effects of NPOs on household education and health issues in the poor areas of the DRC.

NPO impacts on households are still poorly known, as also noted by Mgamassi, Maitland and Tapia $^{29}$, and Omona and Mukuye ${ }^{30}$. In order to get a wide view of the NPO impacts, we used several types of data, such as internet data, quantitative surveys and qualitative discussions with NPO managers and with the local households, which were chosen as randomly as possible in the DRC circumstances. We suggest that our research helps to understand NPO 
effectiveness and the developing country academic research landscape in the context of development activities.

Both case NPOs have an impact on the areas where they are working with tangible, successful results in both health and education. The urban NPO has more impact on perceived health improvement and both of them have an impact on the education improvement among children. However, including several translations of the survey questions, the measurement of effectiveness of NPOs is not an easy task. Further, the definition of a certain education level or health improvement may be quite different in the DRC than in Europe.

The two case NPOs publish reports about their mission accomplishment, thereby adhering to accountability and legitimacy issues. However, the directors have relatively little accounting knowledge and they are under time-constraints to report on their value-adding activities. We can observe that both NPOs define and disclose basically clear objectives each year. However, while the rural NPO discloses strategies and targets in the long term, the urban NPO does not. Both NPOs disclose information about their governing principles and their rules, programmes and activities each year. The rural NPO has more networking activities which helps in recruiting volunteers to work with them. With regard to legitimacy, both neighbourhoods have trust in the NPO integrity and reputation, and both NPOs have more than 10 years of grass root experience in the area. The urban NPO has more press coverage of its activities, and it publishes a monthly newsletter on-line.

As possible limitations in this study it can be highlighted that the survey sample was only about 200 people. However, there was no time to survey more because of the conflict-laden situation in the DRC. Further, each survey took more time than expected and, despite our best efforts, there was still some culture and language barrier between the surveyor (or voluntary worker) typically from Spain, the NPO translator and the interviewed person. However, these issues also reveal some of the difficulties of doing academic research in the developing 
countries using several languages, such as French and Suajili. Our findings, especially the incomparability of reporting together with the lack of reporting guidance and the problematic DRC operating circumstances, suggest that NPO accountability is not a clear concept but require understanding of the context and action at a distance ${ }^{31}$. In conclusion, this highlights the importance of understanding both context and agency issues in academic research and in developing NPOs and accountability relations.

Further research in the area is recommended. For example the different leadership styles of NPO directors might deserve further analysis because managerial issues may be important in understanding the degree of NPO mission accomplishment, accountability and success (in line with James ${ }^{32}$ ). Further, different leadership styles may be contingent on the context in which they are applied. In the DRC, for example, the NPO leaders must currently adapt to new leadership roles surrounded by effectiveness pressures, political uncertainty, financial shortfalls and tight project schedules. Further research is needed, but we suggest that these pressures may have both positive and negative impacts on the ability of the leaders to focus their operations and reach success in pursuing long term goals and in achieving trustworthy accountability relations with the stakeholders.

Other future research lines include analyzing the possibilities and barriers of doing academic research in developing countries, sometimes characterized with extreme conditions. Further, survey designs may need different cultural and language expertise in different areas. Furthermore, when doing survey research an increase in the sample size might be advised, as well as internationally comparative case studies, for example among African countries. However, increasing sample size and reliability in longitudinal analyses may be difficult in the DRC because of the extreme poverty and unstable working and living conditions. Also the NPO surveyors have time-constraints, meaning that if they are surveying they are incurring a high opportunity cost of not working in line with long-term targets. As Olson et al..$^{33}$ noted there can 
be a paradox of improving reporting in order to satisfy stakeholder interests: if the NPO employees are surveying and accounting for their activities, they are neglecting the core operations, such as educational, medicine dispensary or hospital activities. Easy-to-use measures, such as ability to read, may be useful but it is not clear what is counted as reading according to Congolese standards, suggesting difficulty of exact and comparative performance measurement. Finally, considering managerial implications, accounting research might help defining an NPO reporting best practices guide for different development work areas.

\section{Notes}

1. Shapiro and Tambashe, "Gender, poverty, family structure and investments", 360-361.

2. Omona and Mukuye, "Problems of credibility of NGOs", 315-316.

3. Janus, Klingebiel, and Paulo, "Beyond aid", 158-159.

4. Meyer, "A step back as donors", 1118; Sollis, "Multilateral agencies, NGOs and policy reforms", 167-170; Vivian, "NGOs and sustainability", 187-190.

5. World Bank, http://documents.worldbank.org/curated/en/556251468128407787/pdf/359990WDR Ocomplete.pdf; Lehman, "The accountability of NGOs".

6. Lehman, "The accountability of NGOs", 650-653; Jones and Mucha, "Sustainability Assessment and reporting for Nonprofit Organizations", 1485-1488; Read, Taithe, and Mac Ginty, "Data hubris?", 1320.

7. Cheru, "Developing countries and the right to development", 1278.

8. Banks, Hulme and Edwards, "NGOs, States, and Donors revisited", 708-709.

9. Arndt, Jones, and Tarp "Assessing foreign aid's long-run contribution to growth and development", 15; Ceriani and Verme, "The income lever and the allocation of aid", 1520.

10. Valeau, "Stages and Pathways of Development of Nonprofit Organizations", 19101912.

11. Olson, Humphrey, and Guthrie, "Caught in an evaluatory trap: A dilemma for public services under new public financial management." (2001): 505, 506.

12. James et al., "Realities of change".

13. Mgamassi, Maitland and Tapia, "Humanitarian interorganizational Information exchange network", 1500-1502; and see note 2 above.

14. Iwu et al., "Determinants of Sustainability and Organisational Effectiveness in NonProfit Organisations", 9563-9564.

15. Latour, Science in Action, 232; Robson, "Accounting numbers as "inscription": action at a distance and the development of accounting." (1992): 685, 690.

16. Ibid. 
17. See note 15 above; Quattrone and Hopper, "A 'time-space odyssey': management control systems in two multinational organizations" (2005): 735; Reheul and Van Caneghem, "Financial Reporting Lags in the Non-profit Sector", 373-374.

18. Hulme and Edwards, "Too close for comfort?",979-980; Gray and Bebbington, "Environmental accounting, managerialism and sustainability", 38-39.

19. Alnoor, "Accountability in practice", 816-818.

20. McGann and Johnstone, "The power shift and NGO credibility crisis." International Journal of Not-for-Profit Law, 8 (2006): 65-77.

21. Tongia, Subrahmanian, and Arunachalam, Information and communication technology for sustainable development defining a global research agenda.

22. Helmig, Ingerfurth, and Pinz, "Success and Failure of Nonprofit Organizations", 15281532.

23. Besel and Andreescun, "The role of county-based funders in sustaining nonprofits", 262-264.

24. Quattrone and Hopper, "A 'time-space odyssey': management control systems in two multinational organizations." (2005), 736.

25. See e.g. Yin, Case Study Research. Design and Methods, 19.

26. See note 2 above.

27. Tongia, Subrahmanian, and Arunachalam, Information and communications technology for sustainable development.

28. See note 10 above.

29. See note 13 above; and see note 2 above.

30. See note 2 above.

31. See note 15 above.

32. See note 12 above.

33. See note 11 above.

\section{Bibliography}

Alnoor, E. "Accountability in practice: Mechanisms for NGOs." World Development 31, no. 5 (2003): 813-829.

Arndt, C., Jones, S., and Tarp, F. "Assessing foreign aid's long-run contribution to growth and development." World Development, 69 (2015): 6-18.

Banks, N., Hulme, D., and Edwards, M. "NGOs, States, and Donors revisited: Still too close for comfort?" World Development, 66 (2015): 707-718.

Besel, K., and Andreescun, V. "The role of county-based funders in sustaining nonprofits within rural and urbanized countries." Nonprofit Management and Leadership, 13, no. 3 (2003): 253266.

Ceriani, L., and Verme, P. "The income lever and the allocation of aid." The Journal of Development Studies, 50, no. 11 (2014): 1510-1522. 
Cheru, F. "Developing countries and the right to development: a retrospective and prospective African view." Third World Quarterly, 37, no. 7 (2016): 1268-1283.

Gray, R., and Bebbington, J. "Environmental accounting , managerialism and sustainability: Is the planet safe in the hands of business and accounting?" Advances in Environmental Accounting and Management, 1 (2006): 1-44.

Helmig, B., Ingerfurth, S., and Pinz, A. "Success and Failure of Nonprofit Organizations: Theoretical Foundations, empirical evidence and future research." Voluntas: International Journal of Voluntary and Nonprofit Organizations, 25, no. 6 (2014): 1509-1538.

Hulme, D., and Edwards, M. "Too close for comfort? The impact of official aid on management non-governmental organizations." World Development, 24, no. 6 (1996): 961-973.

Iwu, C. G., Kapondoro, L., Twum - Darko, M., and Tengeh, R. "Determinants of Sustainability and Organisational Effectiveness in Non- Profit Organisations." Sustainability, 7 (2015): 9560 9573.

James R., Oladipo, J.; Isosoba,M.; Mboizi, B. and Kusima, I. "Realities of change: How can African NGO leaders develop." In Praxis paper, 6. Oxford: INTRAC, 2005.

Janus, H., Klingebiel, S., and Paulo, S. "Beyond aid: A conceptual perspective on the transformation of development cooperation." Journal of International Development, 27 (2015): 155 - 169.

Jones, K. R., and Mucha, L. "Sustainability Assessment and reporting for Nonprofit Organizations: Accountability "for the public good"." Voluntas: International Journal of Voluntary and Nonprofit Organizations, 25, no. 6 (2014): 1465 - 1482.

Latour, B. Science in Action. How to follow scientists and engineers through society. Harvard University Press, 1987.

Lehman, G. "The accountability of NGOs in civil society and its public spheres." Critical Perspectives on Accounting, 18 (2007): 645 - 669.

McGann, J., and Johnstone, M. "The power shift and NGO credibility crisis." International Journal of Not-for-Profit Law, 8 (2006): 65-77.

Meyer, C. "A step back as donors shift institution building from the public to the private sector." World Development, 20, no. 8 (1992): 1115 - 1126.

Mgamassi, L., Maitland, C., and Tapia, A. H. "Humanitarian interorganizational Information exchange network: How do clique structures impact network effectiveness?" Voluntas: International Journal of Voluntary and Nonprofit Organizations, 25, no. 6 (2014): 1483 - 1508.

Olson, O., Humphrey, C., and Guthrie, J. "Caught in an evaluatory trap: A dilemma for public services under new public financial management." European Accounting Review, 10, no. 3 (2001): 505-522. 
Omona, J., and Mukuye, R. "Problems of credibility of NGOs in Uganda: Implications for theory and practice." Voluntas: International Journal of Voluntary and Nonprofit Organizations, 24, no. 2, (2013): 311-324.

Quattrone, P., and Hopper, T. "A 'time-space odyssey': management control systems in two multinational organizations." Accounting, Organizations and Society, 30, no. 7-8 (2005): 735764.

Read, R., Taithe, B. and Mac Ginty, R. "Data hubris? Humanitarian Information systems and the mirage of technology". Third World Quarterly, 37, no. 8 (2016): 1314-1331.

Reheul, A. M., and Van Caneghem, T. "Financial Reporting Lags in the Non-profit Sector: An Empirical Analysis". Voluntas: International Journal of Voluntary and Nonprofit Organizations, 25, no. 2 (2014): 352 - 377.

Robson, K. "Accounting numbers as "inscription": action at a distance and the development of accounting." Accounting, Organizations and Society, 17, no. 7 (1992): 685-708.

Shapiro, D., and Tambashe, B. "Gender, poverty, family structure and investments in children's education in Kinshasa, Congo." Economics of Education Review, 20 (2001): 359 - 375.

Sollis, P. "Multilateral agencies, NGOs and policy reforms." Development in Practice, 2, no. 3 (1992): 163 - 178.

Tongia, R., Subrahmanian, E., and Arunachalam, V. Information and communications technology for sustainable development, defining a global research agenda. Bangalore: Allied Publishers Pvt. Ltd., 2004.

Valeau, P. J. "Stages and Pathways of Development of Nonprofit Organizations: An Integrative Model." Voluntas: International Journal of Voluntary and Nonprofit Organizations, 26 no. 5 (2015): 1894 - 1919.

Vivian, J. "NGOs and sustainability in Zimbabwe: No magic bullets." Development and Change, 25 (1994): 181 - 209.

World Bank. (2007). Available at:

http://documents.worldbank.org/curated/en/556251468128407787/pdf/359990WDROcompl ete.pdf

Yin, R.K. Case Study Research. Design and Methods. Sage, 2009 (4th ed., original 1984). 